\title{
Silencing MARCH1 suppresses proliferation, migration and invasion of ovarian cancer SKOV3 cells via downregulation of $\mathrm{NF}-\kappa \mathrm{B}$ and $\mathrm{Wnt} / \boldsymbol{\beta}$-catenin pathways
}

\author{
YING MENG, JIANGUO HU, YUHONG CHEN, TINGHE YU and LINA HU \\ Department of Obstetrics and Gynecology, The Second Affiliated Hospital, \\ Chongqing Medical University, Chongqing 400010, P.R. China
}

Received March 23, 2016; Accepted July 27, 2016

DOI: $10.3892 /$ or.2016.5076

\begin{abstract}
Membrane-associated RING-CH (MARCH) belongs to the family of RING-CH type E3 ubiquitin ligases. MARCH1 ubiquitinates and downregulates MHC class II expression in APCs and targets major players of the immune system. However, the role of MARCH1 in ovarian cancer has not been elucidated. The present study investigated the function of MARCH1 in ovarian cancer and the potential mechanisms involved. MARCH1 expression was examined in human ovarian cancer tissue specimens by immunohistochemistry. The role of MARCH1 in ovarian cancer cells was assessed by cell proliferation, migration and invasion assays with MARCH1 gene silencing. To investigate the mechanism by which MARCH1 functions, correlation between MARCH1 and the cell signaling pathways were analyzed using a luciferase reporter assay, real-time RT-PCR, western blot assay and immunofluorescence. MARCH1 was found to be overexpressed in ovarian cancer tissues when compared to adjacent non-tumor and normal ovarian tissues. Silencing MARCH1 inhibited SKOV3 cell proliferation, invasion and migration, as well as inhibiting the NF- $\kappa \mathrm{B}$ and the $\mathrm{Wnt} / \beta$-catenin pathways. MARCH1 functions as a tumor promoter by upregulating the $\mathrm{NF}-\kappa \mathrm{B}$ and the $\mathrm{Wnt} / \beta$-catenin pathways, indicating that MARCH1 may be a therapeutic target for patients with ovarian cancer.
\end{abstract}

\section{Introduction}

The mortality of ovarian cancer is the highest $(1,2)$ of all cancers in women. Due to the difficulty of detection at an early stage, most patients with ovarian cancer are diagnosed at a late

Correspondence to: Dr Lina Hu, Department of Obstetrics and Gynecology, The Second Affiliated Hospital, Chongqing Medical University, 76 Lin Jiang Road, Chongqing 400010, P.R. China E-mail: cqhulina@126.com

Key words: ovarian cancer, MARCH1, NF-кB, Wnt/ $\beta$-catenin, RNAi stage, usually with metastases (3), resulting in poor prognoses. Therefore, any inhibition of metastasis will improve the therapeutic outcome.

Of the 11 membranes in membrane-associated RING-CH (MARCH) family proteins, some molecules play an important part in immune response (4). The RING domain of MARCH1, localized in the cytoplasmic N-terminal region $(5,6)$ participates in the ubiquitin transfer from E2 to its substrate (5). MARCH1 regulates the antigen presentation (7) and T cell costimulatory functions of dendritic cells by attenuating the cell-surface expression of its substrates MHC class II and CD86 molecules (8-10). MARCH1 is also capable of autoregulating its expression through dimerization and autoubiquitination (11). MARCH8, a close homolog of MARCH1 (12), has been identified as a suppressor of the IL-1 $\beta$-induced NF- $\kappa \mathrm{B}$ pathway (13). MARCH8-mediated polyubiquitination (13) and degradation of IL1RAP (14) is an important mechanism for negative regulation of IL-1 $\beta$-induced signaling pathways.

Previous studies of MARCH1 focus on its function in the immune system. However, the role of MARCH1 in tumors has not been clarified. In the present study, we explored the role of MARCH1 in ovarian cancer cells. The results show that MARCH1 is overexpressed in ovarian cancer tissues. Silencing MARCH1 inhibits proliferation, migration and invasion of ovarian cancer cell SKOV3, and downregulates the $\mathrm{NF}-\kappa \mathrm{B}$ and the Wnt/ $\beta$-catenin pathways.

\section{Materials and methods}

Tissue specimens and immunohistochemistry. A tissue microarray (TMA) slide containing malignant and non-neoplastic ovarian tissues $(n=72)$ was provided by US Biomax Inc. Cancer Tissue Bank Collection (US Biomax Inc., Rockville, MD, USA). Another 4 normal ovarian tissues were supplied by the Second Affiliated Hospital of Chongqing Medical University. The use of archived cancer samples was approved by the relevant Ethics Commission. The TMA slide and sample sections were deparaffinized and rehydrated. Antigen was retrieved using $0.01 \mathrm{M}$ sodium-citrate buffer $(\mathrm{pH}$ 6.0) at a sub-boiling temperature for $20 \mathrm{~min}$ after boiling in a microwave oven. The slide and sections were incubated with $3 \%$ hydrogen peroxide for $10 \mathrm{~min}$ to block endogenous peroxidase. 
After 15 min of pre-incubation in 5\% normal goat serum to prevent non-specific staining, the samples were incubated with the antibody to MARCH1 (1:1001; bs-9335R; Bioss, Beijing, China) at $4^{\circ} \mathrm{C}$ overnight. Secondary (Bioss Biotechnology) antibody was added and incubated for $30 \mathrm{~min}$. The section was incubated in horseradish enzyme-labeled chain avidin solution (Bioss Biotechnology) for $30 \mathrm{~min}$ at room temperature. Color was developed using a diaminobenzidine (DAB) substrate kit. Counterstaining was carried out with hematoxylin.

MARCH1 immunoreactivity was graded as follows: 0 (absence of staining), 1 (weakly stained), 2 (moderately stained) and 3 (strongly stained). The percentage of positive tumor cells was scored as follows: 0 (absence of positive cells), 1 ( $\leq 33 \%$ positive tumor cells), 2 (33-66\% positive tumor cells) and 3 ( $\geq 66 \%$ positive tumor cells). The staining score was calculated (staining intensity score $\mathrm{x}$ the percentage score), and the criteria was as absence: $\mathrm{IHC}=0$, weak; $>0$ IHC $\leq 4$; and strong, $\geq 5$ IHC $\leq 9$ ). The Mann-Whitney U test was used to assess the associations between MARCH1 overexpression and clinicopathological variables of epithelial ovarian cancer $(\mathrm{EOC})(\mathrm{n}=45)$ samples.

Cell culture and transfection. Human ovarian cancer SKOV3 cells were cultured in RPMI-1640 medium (Thermo Scientific, Waltham, MA, USA) supplemented with $10 \%$ fetal bovine serum (FBS) (Kang Yuan Biology, China) and 1\% antibiotics (Beyotime, Tianjin, China) at $37^{\circ} \mathrm{C}$ and $5 \% \mathrm{CO}_{2}$.

Small interfering RNAs (siRNAs) for MARCH1 and negative control (NC) siRNAs were synthesized by GenePharma Co., Ltd. (Shanghai, China). MARCH1 or NC siRNAs were transfected into SKOV3 cell using a transfection kit from GenePharma Co., Ltd., according to the manufacturer's protocol. The sequences for MARCH1 siRNA were: 444, 5'-GCAAGUAUGACUUCAUAAUTT-3' and 5'-AUUAUGAA GUCAUACUUGCTT-3'; 540, 5'-CUGUCACAUUCCACGU AAUTT-3' and 5'-AUUACGUGGAAUGUGACAGTT-3'; 693, 5'-CAGGAGGUCUUGUCUUCAUTT-3' and 5'-AUGAAGA CAAGACCUCCUGTT-3'.

Scratch assay. Cells were plated into a 6-well plate with complete medium and grown to 50\% confluence. The medium was then replaced with antibiotic-free medium. Cells were transfected, and the medium was replaced with complete medium $24 \mathrm{~h}$ after transfection. When cells were grown to $100 \%$ confluence, a wound was created by scraping the confluent monolayer cells with a p200 pipette tip. Cells were then grown in medium supplemented with $1 \%$ FBS. The distance between the two sides of cell-free area was photographed using 10x objective in an Olympus photomicroscope, and was measured by Matrigel invasion assays at 0,24 and $48 \mathrm{~h}$. All experiments were performed in triplicate.

Transwell invasion assay. Cellular migration was determined using a Transwell assay. Cells were transfected for $48 \mathrm{~h}$ and subsequently dissociated. Cells $\left(1.0 \times 10^{5}\right)$ were re-suspended in medium-free of serum and growth factors, and placed in the upper chamber with an $8-\mu \mathrm{m}$ pore, $6.5-\mathrm{mm}$ polycarbonate filter (Corning, New York, NY, USA) coated with Matrigel basement membrane matrix (BD Biosciences, Bedford, MA, USA) for $2 \mathrm{~h}$ at $37^{\circ} \mathrm{C}$ before cells were added. The insert was placed in a well with complete medium. Cells were incubated for $48 \mathrm{~h}$, and cells that did not migrate through the pores were removed with a cotton swab. Cells on the lower surface of the membrane were fixed in $4 \%$ paraformaldehyde, stained with $0.5 \%$ crystal violet (Beyotime), and counted under a microscope (magnification, $\mathrm{x} 200$ ).

Cell viability. Cell growth was analyzed using a WST-8 assay (Dojindo Laboratories, Kumamoto, Japan). Cells were plated in a 96-well plate with a density of $5 \times 10^{3}$ cells/well and siRNA was transfected after $24 \mathrm{~h}$. Cell viability was determined at 24 , $48,72,96$ and $120 \mathrm{~h}$.

5-Ethynyl-2'-deoxyuridine (EdU)-based proliferation assay. Cell proliferation was measured by the EdU DNA Cell Proliferation kit (RiboBio) according to the manufacturer's protocol.

$R N A$ isolation and real-time $R T-P C R$ with reverse transcription. Total RNA was isolated using the High-purity Total RNA Rapid Extraction kit (RP1201; BioTeke, Beijing, China). Real-time RT-PCR was performed using iScript cDNA Synthesis and SYBR-Green Gene Expression Assay kits (Bio-Rad, Philadelphia, PA, USA). Real-time RT-PCR and data collection were performed on a CFX96 instrument (Bio-Rad).

Western blot analysis. Total protein was extracted using cell lysis buffer, and the protein concentration was determined using the BCA assay (both from Beyotime). Protein (100 $\mu \mathrm{g}$ ) was subjected to SDS-PAGE, and then transferred to polyvinylidene fluoride membranes (Millipore, Bedford, MA, USA). The membranes were blocked for $2 \mathrm{~h}$ in $5 \%$ skimmed milk (Difco Laboratories, Detroit, MI, USA). Then, a membrane was incubated with the primary antibodies, including polyclonal rabbit anti-MARCH1 antibody (1:200; bs-9335R; Bioss), polyclonal rabbit anti-NF-кB p65 (1:1,000; ab7970), polyclonal rabbit anti-NF- $\mathrm{B}$ p50 (1:1,000; ab7971) (both from Abcam Inc., Cambridge, MA, USA), polyclonal rabbit anti- $\beta$-catenin antibody (1:500; bs-1165R; Bioss), polyclonal rabbit anti-Histone H1, and polyclonal rabbit anti-E-cadherin antibody, overnight at $4^{\circ} \mathrm{C}$. The membrane was incubated with the HRP-conjugated secondary antibody for $2 \mathrm{~h}$. GAPDH was detected with a polyclonal antibody and served as the reference (1:1,000; AB10016; Sangon Biotech, Shanghai, China). Proteins were visualized with the ECL system (Beyotime) using the ChemiDoc XRS system (Bio-Rad).

Immunofluorescence microscopy. Cells were transfected with siRNAs. After $48 \mathrm{~h}$, cells were fixed with $4 \%$ paraformaldehyde and stained with immunofluorescence. Hoechst was used to label the nucleus.

Luciferase reporter assay. Cells were seeded on a 24-well plate, and transfected with siRNAs. After $48 \mathrm{~h}$, cells were transfected (GeneCopoeia) with 500 ng TOP flash or NF- $\kappa \mathrm{B}$ reporter and $10 \mathrm{ng}$ pRL-TK (Promega, Madison, WI, USA) plasmids using EndoFectin ${ }^{\mathrm{TM}}$-Plus. Assays were performed in accordance with the dual-luciferase assay specifications (Promega) using the Mithras LB 940 luminometer (Berthold, 
A

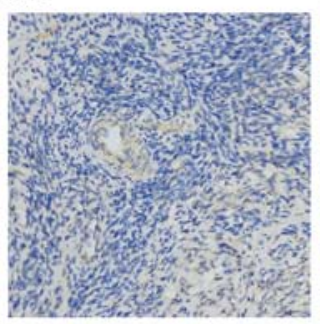

E

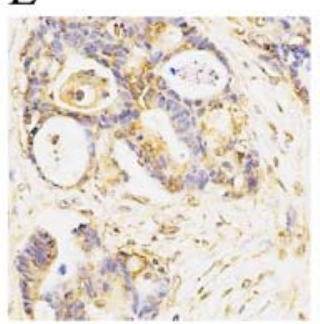

I

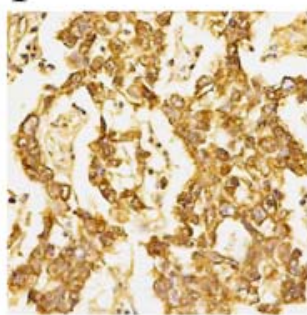

B

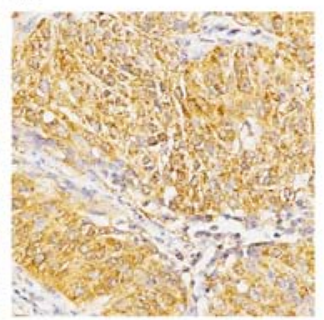

F

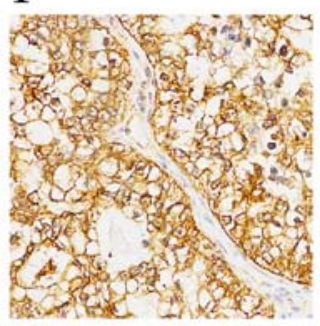

J

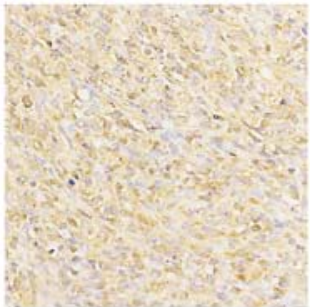

C

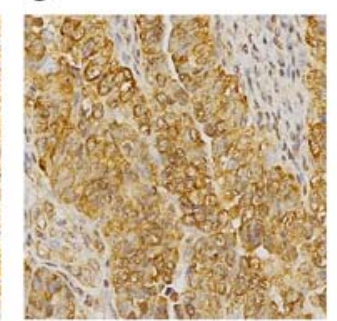

G

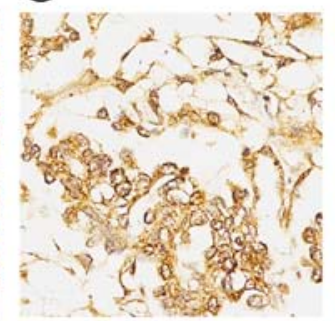

K

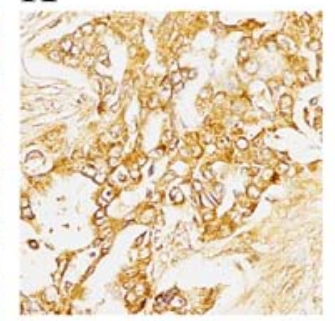

D

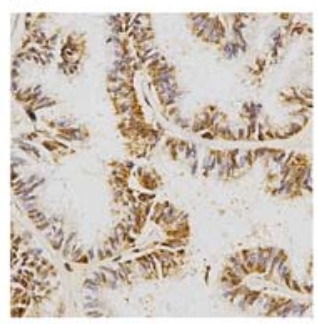

$\mathrm{H}$

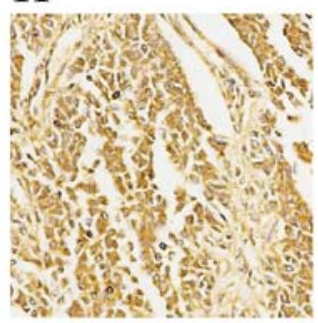

L

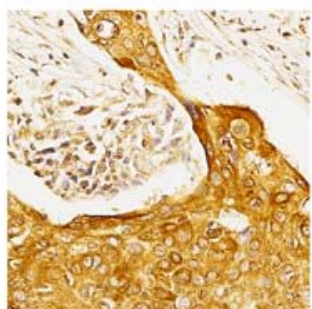

Figure 1. Expression of MARCH1 in normal/benign ovary, and ovarian cancer tissue samples by immunohistochemical staining. (A) Normal ovary. (B) Serous adenocarcinoma. (C) Papillary serous adenocarcinoma. (D) Mucinous adenocarcinoma. (E) Endometrioid carcinoma. (F) Clear-cell carcinoma. (G) Endodermal sinus carcinoma. (H) Granular cell carcinoma. (I) Dysgerminoma. (J) Theca cell tumors. (K) Metastatic adenocarcinoma. (L) Cancerous mature ovarian teratoma. MARCH1 staining was predominantly located in the cytoplasm and the cytomembrane of ovarian cancer tissues. MARCH1 expression was undetectable in normal ovarian tissues.

Bad Wildbad, Germany). The activity of firefly luciferase was normalized to measure the transfection efficiency. All experiments were performed at least 3 times.

Statistical analysis. All statistical analyses were performed using SPSS 17.0 software (SPSS, Inc., Chicago, IL, USA). Data are presented as mean \pm standard deviation and Student's t-test or ANOVA was used. Statistical significance was set at $\mathrm{p}<0.05$.

\section{Results}

Immunohistochemistry profile of MARCH1 in normal/benign ovary and ovarian cancer tissue samples. The immunohistochemistry results demonstrated a negative expression of MARCH1 in normal and para-cancerous normal ovary tissue (Fig. 1). Of the primary ovarian cancer samples $(n=63)$, $34(54.97 \%)$ had high expression and 29 (46.03\%) had low expression. In order to determine whether MARCH1 expression correlates to clinicopathological type, epithelial ovarian cancer (EOC) tissues $(n=45)$ were grouped into serous and non-serous (mucinous, clear-cell and endometrioid) cancers. No correlation between MARCH1 expression and clinicopathological variables are noted (Table I).

MARCHI expression in ovarian cancer cell lines. The mRNA level of MARCH1 in ovarian cancer cell lines A2780,
Table I. Association of MARCH1 expression with clinicopathological characteristics in 45 patients with EOC.

\section{MARCH1 expression}

\begin{tabular}{lcrrr} 
Characteristics & $\begin{array}{c}\text { No. of pts. } \\
(\mathrm{n}=45)\end{array}$ & $\begin{array}{c}\text { Low no. } \\
(\%)\end{array}$ & $\begin{array}{c}\text { High no. } \\
(\%)\end{array}$ & P-value \\
\hline $\begin{array}{l}\text { Age (years) } \\
\quad 51\end{array}$ & 28 & $12(42.86)$ & $16(57.14)$ & 0.913 \\
$\geq 51$ & 17 & $7(41.18)$ & $10(58.82)$ & \\
FIGO stage & & & & 0.625 \\
I-II & 36 & $16(44.44)$ & $20(55.56)$ & \\
III-IV & 9 & $3(33.33)$ & $6(66.67)$ & \\
Grade & & & & 0.202 \\
$\quad 1-2$ & 24 & $8(33.33)$ & $16(66.67)$ & \\
3 & 21 & $11(52.38)$ & $10(47.62)$ & \\
$\quad \begin{array}{l}\text { Tumor type } \\
\text { Serous }\end{array}$ & 38 & $16(42.11)$ & $22(57.89)$ & \\
$\quad$ Non-serous & & $3(42.86)$ & $4(57.14)$ & \\
\hline
\end{tabular}

MARCH1, membrane-associated RING-CH; EOC, epithelial ovarian cancer; pts., patients; FIGO, International Federation of Gynecology and Obstetrics. ${ }^{a}$ Non-serous EOC included mucinous, clear and endometrioid cancer. 

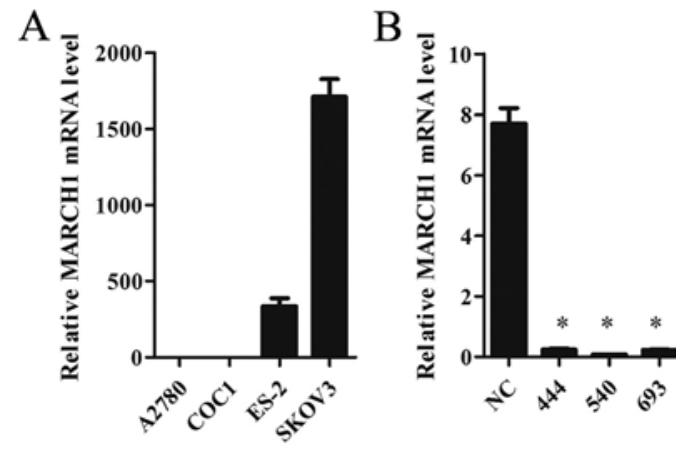

$\mathrm{C}$

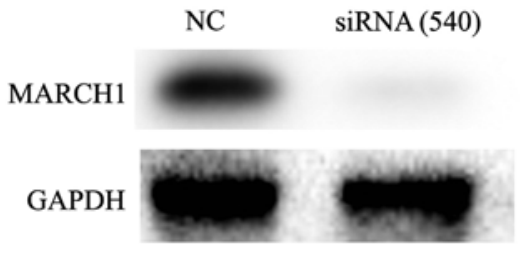

Figure 2. MARCH1 expression in ovarian cancer cell lines. (A) The highest level was detected in SKOV3. (B) The effect of siRNAs on silencing MARCH1 in SKOV3 cell. (C) 540 displayed the most efficient inhibition; ${ }^{\text {p }}<0.05$ vs. the NC (negative control).

A

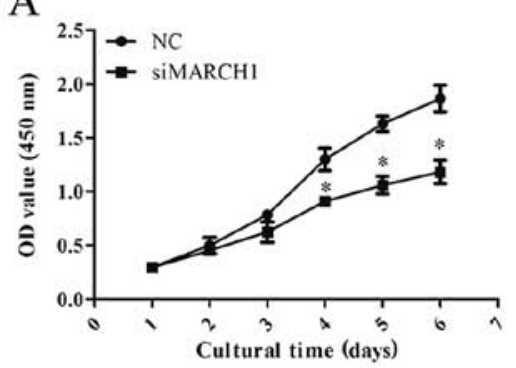

B
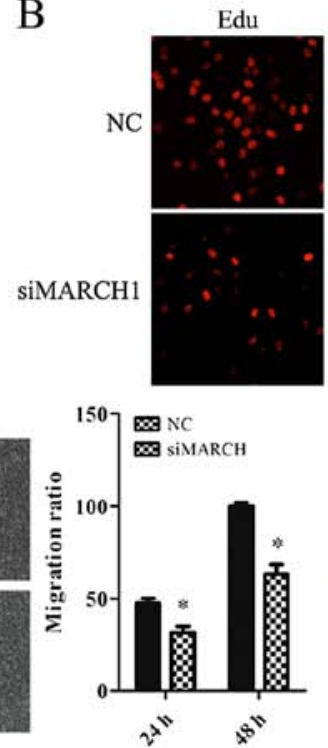

Hoechst

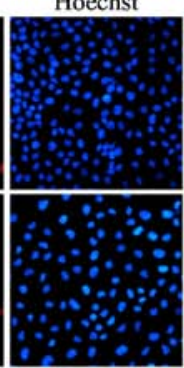

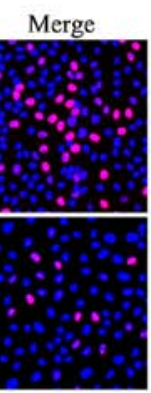

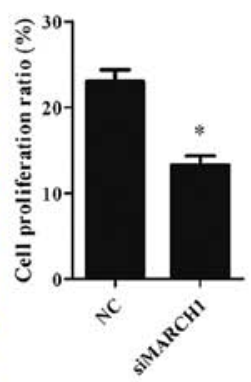

$\mathrm{C}$

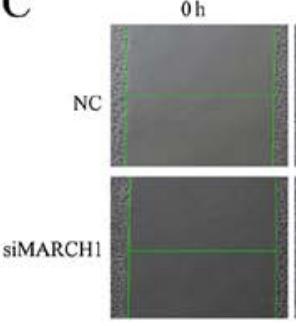

$24 \mathrm{~h}$

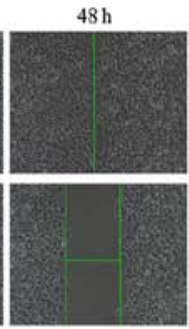

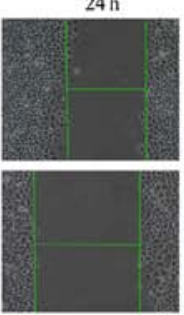

Figure 3. The effect of silencing MARCH1 on cell proliferation, migration, and invasion in vitro. Cell proliferation was examined by CCK-8 assay: (A) silencing MARCH1 resulted in significant growth-inhibition from day 2. EdU-based proliferation assay was performed $48 \mathrm{~h}$ after RNA interference. At the proliferation stage the nuclei were dyed red with EdU. All nuclei were dyed blue with Hoechst. (B) Red and blue were merged into magenta to show the proportion of nuclei with proliferation. Proliferation of MARCH1-silenced cells was clearly inhibited. Downregulation of MARCH1 resulted in a decrease in (C) cell-migrated and (D) -invaded cells; " $\mathrm{p}<0.05$ vs. the NC.

COC1, ES-2 and SKOV3 was analyzed. The highest level was detected in SKOV3 cells (Fig. 2A), so these were chosen for a knockdown trial. Of the 3 siRNA sequences, 540 was found to be the most suitable one for our purposes (Fig. 2B), and was thus used in all subsequent experiments.

Knockdown of MARCH1 inhibits cell proliferation, migration and invasion. The effect of MARCH1 on the cell biological behavior was analyzed. Cell Counting Kit-8 (CCK-8) and EdU assays showed that the proportion of proliferating cells was reduced in MARCH1-silenced cells (Fig. 3A and B). The scratch assay showed that migration ability was impaired in MARCH1-silenced cells (Fig. 3C). The invasion assay showed a decrease in invaded cells (Fig. 3D).

$I L-1 \beta, T N F-\alpha$ and TGF- $\beta$ positively regulated MARCHI expression. In order to determine whether IL-1 $\beta$ affects MARCH1 expression, cells were treated with IL-1 $\beta$ in a range of concentrations: $0,10,20$ and $30 \mathrm{ng} / \mathrm{ml}$. MARCH1 expression, validated by real-time qT-PCR and western blotting, was upregulated by IL-1 $\beta$, with the highest level noted correlating to a concentration of $10 \mathrm{ng} / \mathrm{ml}$ (Fig. $4 \mathrm{~A}$ and B).

IL-1 $\beta$ affected tumor cells by activating the canonical NF- $\kappa$ B pathway. TNF- $\alpha$ and TGF- $\beta$ are also capable of activating the NF- $\kappa \mathrm{B}$ pathway. Thus, cells were treated with TNF- $\alpha$ or TGF- $\beta$ and MARCH1 was assayed. The results showed that TNF- $\alpha$ and TGF- $\beta$ upregulated MARCH1 expression at mRNA and protein levels (Fig. 4A and B).

Knockdown of MARCH1 inhibits NF- $\kappa$ B activity as well as the transportation of $p 65$ and p50 to the nucleus. In order to determine whether MARCH1 affects the NF- $\kappa B$ pathway, $N F-\kappa B$ activity was measured using NF- $\kappa B$ luciferase reporter. The results showed that NF- $\kappa B$ activity was inhibited in MARCH1-silenced cells (Fig. 5A).

p50 and p65 are sub-units of the transcription factor NF- $\kappa B$ (15). They can bind DNA individually as a homodimer or as a p50-p65 heterodimer (16), thus, activating transcription 
A
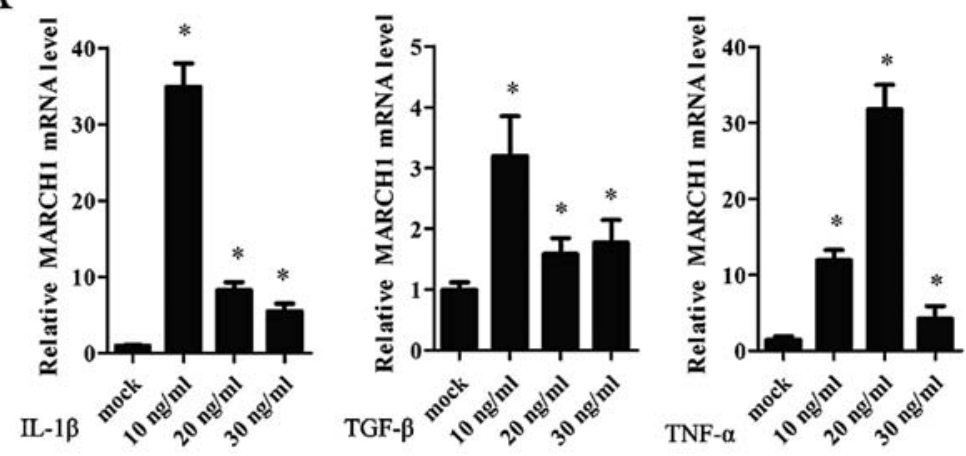

B
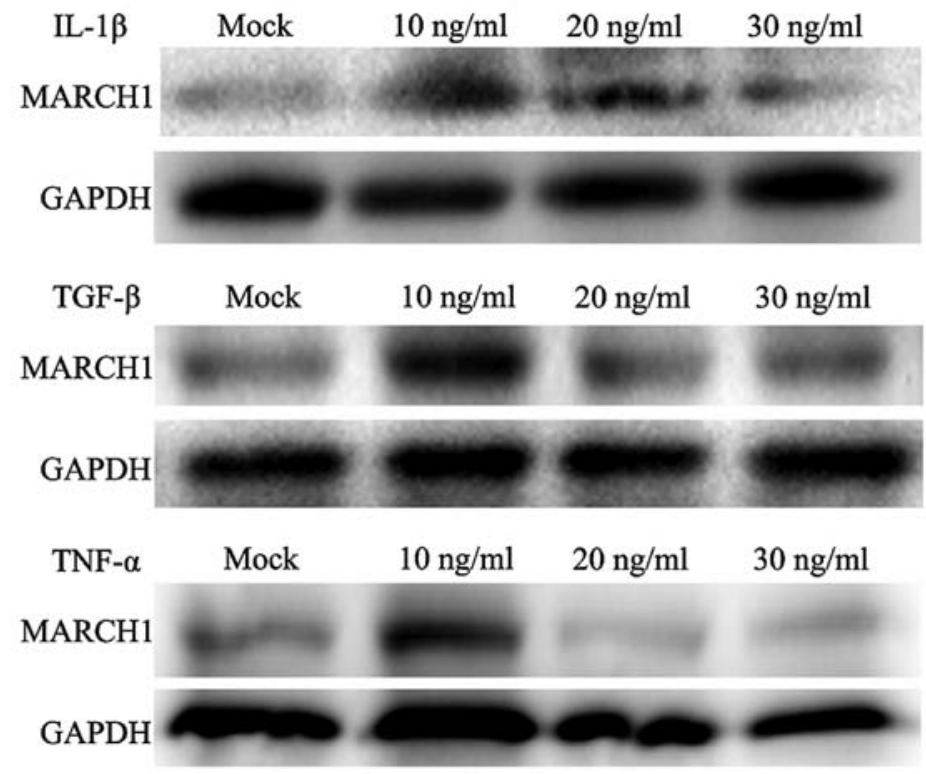

Figure 4. The effect of IL-1 $\beta$, TNF- $\alpha$ and TGF- $\beta$ on MARCH1 expression detected by (A) qPCR and (B) western blotting: these 3 cytokines upregulated MARCH1 expression; " $\mathrm{p}<0.05$ vs. mock group.

of these genes. Therefore, we hypothesized that MARCH1 may affect the NF- $\mathrm{kB}$ pathway by regulating $\mathrm{p} 65$ and $\mathrm{p} 50$. To verify this hypothesis, p65 and p50 expression was validated by western blotting. The MARCH1-silenced group was found to have a lower total expression of p50 and p65, and a decrease in the nucleus of p65 and p50 (Fig. 5B). Moreover, the immunofluorescence assay indicated that silencing MARCH1 attenuated nuclear translocation of p65 and p50 (Fig. 5C).

MARCH1 expression is mediated through an $N F-\kappa B$-dependent pathway. IL-1 $\beta$ can activate the NF- $\kappa \mathrm{B}$ pathway (17). As IL-1 $\beta$ was proved to increase MARCH1, we tested whether the IL-1-mediated induction of MARCH1 occurred through an NF- $\kappa B$-dependent pathway. Pyrrolidine dithiocarbamate (PDTC), an inhibitor of NF-אB (18), was used to block the NF- $\mathrm{BB}$ pathway. MARCH1 expression decreased at both mRNA and protein levels (Fig. 5D and E). Furthermore, when NF- $\mathrm{BB}$ pathway was inhibited by silencing p65 and p50 with siRNAs, MARCH1 was downregulated (Fig. 5F).

Knockdown of MARCH1 inhibits Wnt/ $\beta$-catenin pathway. Wnt targets LEF1, c-MYC and SP5 proteins (19-21). Silencing MARCH1 was found to downregulate LEF1,
c-MYC and SP5 at the mRNA level (Fig. 6A). TOP-flash luciferase reporter was used to determine whether MARCH1 mediated the $\mathrm{Wnt} / \beta$-catenin pathway. MARCH1-silenced cells showed lower levels of activity compared to the NC group (Fig. 6B). We also examined $\beta$-catenin expression in MARCH1-silenced cells. The data showed that silencing MARCH1 significantly decreased $\beta$-catenin expression at the protein level (Fig. 6C). Furthermore, the immunofluorescence results indicated that silencing MARCH1 inhibits the translocation of $\beta$-catenin to the nucleus (Fig. 6D). These results indicate that MARCH1 can upregulate the Wnt/ $\beta$ catenin pathway.

Knockdown of MARCHI negatively regulated E-cadherin. E-cadherin is a tumor suppressor $(22,23)$. It can bind and antagonize the nuclear signaling function of $\beta$-catenin (24), a known proto-oncogene. E-cadherin inhibits the Wnt/ $\beta$-catenin pathway by binding with $\beta$-catenin and inducing its degradation $(25,26)$. MARCH1 may affect E-cadherin expression. E-cadherin expression in MARCH1 knockdown cells and $\mathrm{NC}$ cells was therefore observed. The results showed that loss of MARCH1 protein resulted in higher levels of E-cadherin protein expression (Fig. 6E). 
A

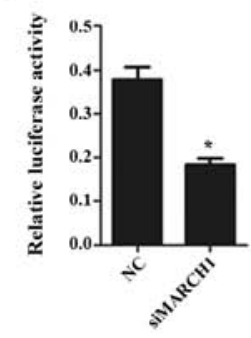

E

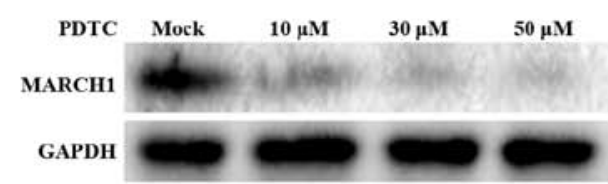

B

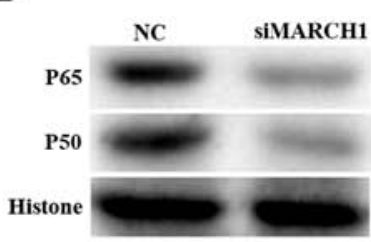

C

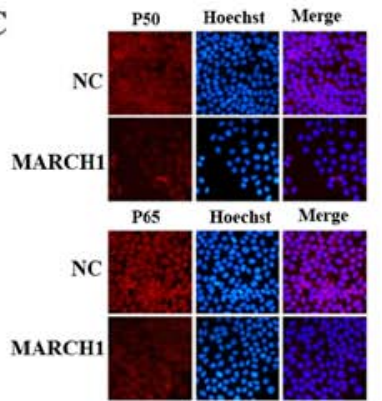

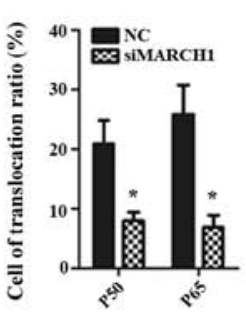

D

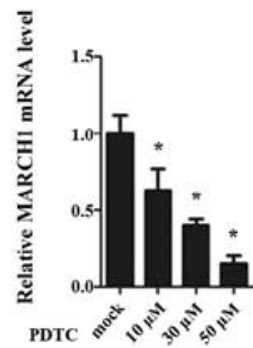

$\mathrm{F}$

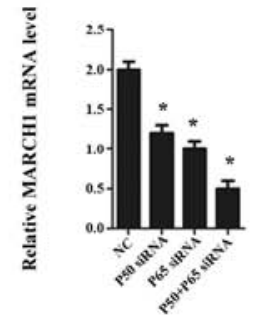

G

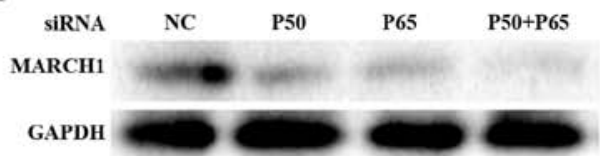

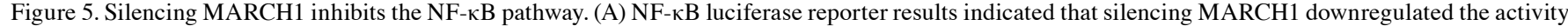
of the NF- $\mathrm{B}$ pathway. Silencing MARCH1 inhibited p50 and p65 expression at the (B) nucleus protein level and (C) attenuated translocation of p50 and p65. Inhibiting the NF- $\kappa$ B pathway by PDTC. MARCH1 expression was decreased at (D) mRNA and (E) protein levels. (F) Silencing p50 and p65 by siRNA reduced MARCH1 expression at both mRNA and $(\mathrm{G})$ protein level; ${ }^{*} \mathrm{p}<0.05$ vs. the NC or mock group.

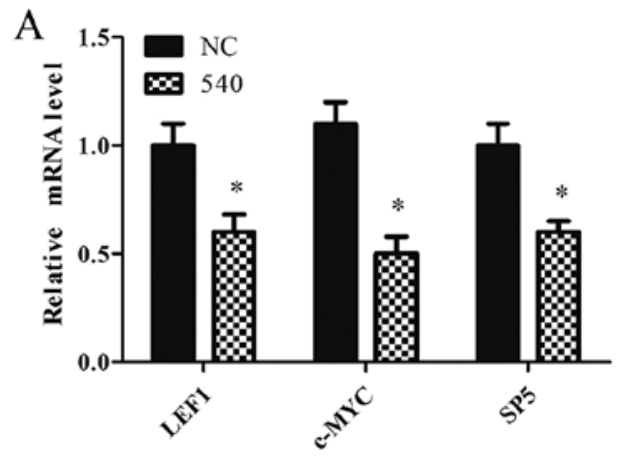

D

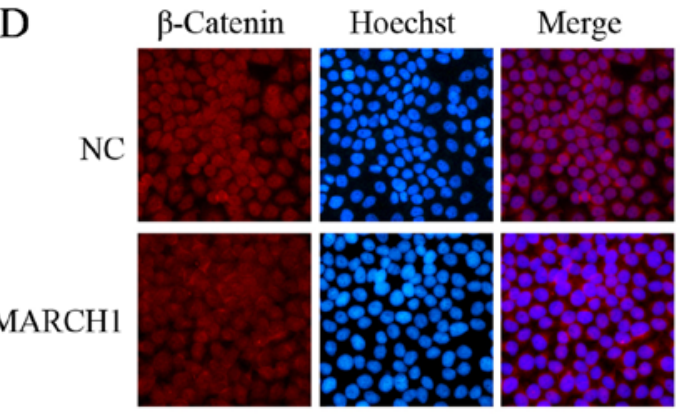

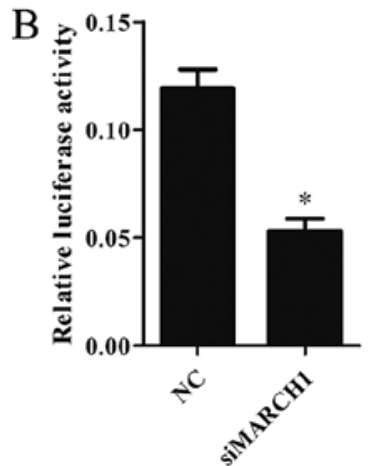

$\mathrm{C}$
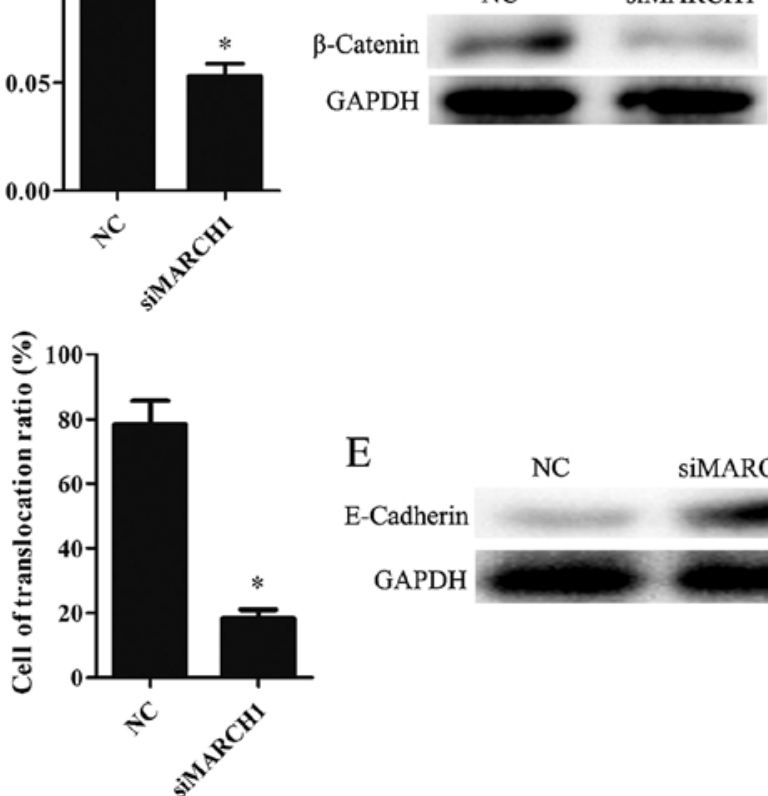

$\mathrm{E}$

E-Cadherin

GAPDH

Figure 6. Silencing MARCH1 inhibits the Wnt/ $\beta$-catenin pathway. (A) The Wnt pathway-targeted genes decreased at mRNA level in MARCH1-silenced cells. (B) TOP-flash luciferase reporter results showed that silencing MARCH1 downregulated the Wnt/ $\beta$-catenin pathway. (C) Silencing MARCH1 inhibited $\beta$-catenin protein expression and (D) attenuated the translocation of $\beta$-catenin into the nucleus. (E) E-cadherin protein expression was enhanced in MARCH1 silenced cells; " $\mathrm{p}<0.05$ vs. the NC or mock group.

\section{Discussion}

Previous studies of MARCH1 have mainly focused on its function in the immune system. The role of MARCH1 in tumors has thus remained unclear. The present study shows that MARCH1 is overexpressed in ovarian cancer tissues, and that silencing MARCH1 inhibited proliferation, migration and invasion of ovarian cancer SKOV3 cells. Additionally, silencing MARCH1 inhibits the NF- $\mathrm{kB}$ and the Wnt/ $\beta$-catenin pathways.

The immunohistochemistry results showed a high level of MARCH1 expression in cancer tissues, while adjacent normal 
ovarian tissues were weakly stained and normal ovarian tissues were negatively stained. However, clinicopathological variables did not correlate to MARCH1 expression. This may be due to the limited sample size, and should be verified in a larger-scale trial. Nevertheless, silencing MARCH1 was found to inhibit SKOV3 cell proliferation, invasion and migration. These data suggest that MARCH1 could play an important role in the formation, development and metastasis of ovarian cancer.

Cytokines have an impact on the cancer progress via modulating tumor microenvironment and cell signaling pathways $(27,28)$. For instance, L- $1 \beta$, TNF- $\alpha$ and TGF- $\beta$ can activate the $\mathrm{NF}-\kappa \mathrm{B}$ pathway $(29,30)$, thereby regulating the biological behavior of cancer cells $(15,29,31)$. The present study showed that L-1 $\beta$, TNF- $\alpha$ and TGF- $\beta$ all upregulate MARCH1 expression. Silencing MARCH1 led to an inhibition of the behavior of ovarian cancer cells. Thus, a correlation may exist between MARCH1 and the NF- $\mathrm{BB}$ pathway, which was confirmed by the findings in the cell signaling pathway reporter assays.

$N F-\kappa B$ can activate the transcription of several genes involved in the regulation of numerous important processes such as immune response, inflammation (30), apoptosis $(32,33)$ and cell proliferation $(34,35)$. Aberrant activation of $\mathrm{NF}-\kappa \mathrm{B}$ signaling is related to various human cancers $(15,36)$ including ovarian cancer $(36,37)$. Silencing MARCH1 can not only downregulate the expression of $\mathrm{NF}-\kappa \mathrm{B}, \mathrm{p} 65$ and p50, but also sequester p65-p50 in the cytoplasm. These results imply that MARCH1 positively regulates the $N F-\kappa B$ pathway. IL-1 induces $N F-\kappa B$ activation in a dose-dependent manner (17). IL-1 $\beta$ increases the protein level of p65 in the nucleus at low concentration but decreases it at high concentration (38). These findings are consistent with the data generated by the present study. In addition, we assumed that $\mathrm{NF}-\kappa \mathrm{B}$ regulated $\mathrm{MARCH} 1$, reversely. The present study showed that inhibiting the $\mathrm{NF}-\kappa \mathrm{B}$ pathway, whether by PDTC or by silencing p50 and p65, downregulated MARCH1 expression at the protein level. In conclusion, IL-1 $\beta$ upregulates MARCH1, which positively regulates the $\mathrm{NF}-\kappa \mathrm{B}$ pathway. In addition, the $\mathrm{NF}-\kappa \mathrm{B}$ pathway can upregulate MARCH1.

The Wnt/ $\beta$-catenin pathway is involved in the aggressive behavior of cancer cells. E-cadherin inhibits the Wnt/ $\beta$-catenin pathway by binding with $\beta$-catenin and inducing its degradation. Overexpression of $\beta$-catenin increases tumor migration and invasion (39). MARCH1, as a tumor promoter in ovarian cancer, was found to upregulate $\beta$-catenin at a post-transcriptional level, thereby facilitating the translocation of $\beta$-catenin into the nucleus. These results indicate that MARCH1 downregulates E-cadherin, leading to an accumulation of $\beta$-catenin in plasma, which contributes to upregulation of the $\mathrm{Wnt} / \beta$-catenin pathway.

In conclusion, our data provide clinical and laboratory evidence that MARCH1 expression plays an important role in the progression of ovarian cancer and, therefore, may be a novel therapeutic target.

\section{Acknowledgements}

The present study was supported by the National Natural Science Foundation of China (grant no. 81172492), the
Specialized Research Fund fo rthe Doctoral Program of Higher Education (grant no. 20125503110004) and the Key Project of Science and Technology of Chongqing (grant no. CSTC2012JJB10030).

\section{References}

1. Kandukuri SR and Rao J: FIGO 2013 staging system for ovarian cancer: What is new in comparison to the 1988 staging system? Curr Opin Obstet Gynecol 27: 48-52, 2015.

2. Tew WP and Fleming GF: Treatment of ovarian cancer in the older woman. Gynecol Oncol 136: 136-142, 2015.

3. Musto A, Grassetto G, Marzola MC, Rampin L, Chondrogiannis S, Maffione AM, Colletti PM, Perkins AC, Fagioli G and Rubello D: Management of epithelial ovarian cancer from diagnosis to restaging: An overview of the role of imaging techniques with particular regard to the contribution of 18F-FDG PET/CT. Nucl Med Commun 35: 588-597, 2014.

4. Nathan JA and Lehner PJ: The trafficking and regulation of membrane receptors by the RING-CH ubiquitin E3 ligases. Exp Cell Res 315: 1593-1600, 2009.

5. Ohmura-Hoshino M, Goto E, Matsuki Y, Aoki M, Mito M, Uematsu $\mathrm{M}$, Hotta $\mathrm{H}$ and Ishido $\mathrm{S}$ : A novel family of membrane-bound E3 ubiquitin ligases. J Biochem 140: 147-154, 2006.

6. Jabbour M, Campbell EM, Fares H and Lybarger L: Discrete domains of MARCH1 mediate its localization, functional interactions, and posttranscriptional control of expression. $J$ Immunol 183: 6500-6512, 2009.

7. Bourgeois-Daigneault MC and Thibodeau J: Identification of a novel motif that affects the conformation and activity of the MARCH1 E3 ubiquitin ligase. J Cell Sci 126: 989-998, 2013.

8. Corcoran K, Jabbour M, Bhagwandin C, Deymier MJ, Theisen DL and Lybarger L: Ubiquitin-mediated regulation of CD86 protein expression by the ubiquitin ligase membrane-associated RING-CH-1 (MARCH1). J Biol Chem 286: 37168-37180, 2011.

9. Tze LE, Horikawa K, Domaschenz H, Howard DR, Roots CM, Rigby RJ, Way DA, Ohmura-Hoshino M, Ishido S, Andoniou CE, et al: CD83 increases MHC II and CD86 on dendritic cells by opposing IL-10-driven MARCH1-mediated ubiquitination and degradation. J Exp Med 208: 149-165, 2011.

10. Chattopadhyay G and Shevach EM: Antigen-specific induced $T$ regulatory cells impair dendritic cell function via an IL-10/MARCH1-dependent mechanism. J Immunol 191: 5875-5884, 2013

11. Bourgeois-Daigneault MC and Thibodeau J: Autoregulation of MARCH1 expression by dimerization and autoubiquitination. J Immunol 188: 4959-4970, 2012.

12. Matsuki Y, Ohmura-Hoshino M, Goto E, Aoki M, Mito-Yoshida M, Uematsu M, Hasegawa T, Koseki H, Ohara O, Nakayama M, et al: Novel regulation of MHC class II function in B cells. EMBO J 26: 846-854, 2007.

13. Chen R, Li M, Zhang Y, Zhou Q and Shu HB: The E3 ubiquitin ligase MARCH8 negatively regulates IL-1 $\beta$-induced NF- $\kappa$ B activation by targeting the IL1RAP coreceptor for ubiquitination and degradation. Proc Natl Acad Sci USA 109: 14128-14133, 2012.

14. van de Kooij B, Verbrugge I, de Vries E, Gijsen M, Montserrat V, Maas C, Neefjes J and Borst J: Ubiquitination by the membrane-associated RING-CH-8 (MARCH-8) ligase controls steady-state cell surface expression of tumor necrosis factorrelated apoptosis inducing ligand (TRAIL) receptor 1. J Biol Chem 288: 6617-6628, 2013.

15. Hayden MS and Ghosh S: Signaling to NF-kappaB. Genes Dev 18: 2195-2224, 2004

16. Fujita T, Nolan GP, Ghosh S and Baltimore D: Independent modes of transcriptional activation by the p50 and p65 subunits of NF-kappa B. Genes Dev 6: 775-787, 1992.

17. Woronicz JD, Gao X, Cao Z, Rothe M and Goeddel DV: IkappaB kinase-beta: NF-kappaB activation and complex formation with IkappaB kinase-alpha and NIK. Science 278: 866-869, 1997.

18. Schreck R, Albermann K and Baeuerle PA: Nuclear factor kappa B: An oxidative stress-responsive transcription factor of eukaryotic cells (a review). Free Radic Res Commun 17: 221-237, 1992.

19. Logan CY and Nusse R: The Wnt signaling pathway in development and disease. Annu Rev Cell Dev Biol 20: 781-810, 2004. 
20. Neth P, Ries C, Karow M, Egea V, Ilmer M and Jochum M: The Wnt signal transduction pathway in stem cells and cancer cells: Influence on cellular invasion. Stem Cell Rev 3: 18-29, 2007.

21. Katoh $\mathrm{M}$ and Katoh M: WNT signaling pathway and stem cell signaling network. Clin Cancer Res 13: 4042-4045, 2007.

22. Cheng CW, Wu PE, Yu JC, Huang CS, Yue CT, Wu CW and Shen CY: Mechanisms of inactivation of E-cadherin in breast carcinoma: Modification of the two-hit hypothesis of tumor suppressor gene. Oncogene 20: 3814-3823, 2001.

23. Berx G, Cleton-Jansen AM, Nollet F, de Leeuw WJ, van de Vijver M, Cornelisse C and van Roy F: E-cadherin is a tumour/invasion suppressor gene mutated in human lobular breast cancers. EMBO J 14: 6107-6115, 1995.

24. Gottardi CJ, Wong E and Gumbiner BM: E-cadherin suppresses cellular transformation by inhibiting beta-catenin signaling in an adhesion-independent manner. J Cell Biol 153: 1049-1060, 2001.

25. Clevers H: Wnt/beta-catenin signaling in development and disease. Cell 127: 469-480, 2006.

26. Nelson WJ and Nusse R: Convergence of Wnt, beta-catenin, and cadherin pathways. Science 303: 1483-1487, 2004.

27. Mantovani A, Allavena P, Sica A and Balkwill F: Cancer-related inflammation. Nature 454: 436-444, 2008.

28. Liotta LA and Kohn EC: The microenvironment of the tumourhost interface. Nature 411: 375-379, 2001.

29. Tak PP and Firestein GS: NF-kappaB: A key role in inflammatory diseases. J Clin Invest 107: 7-11, 2001.

30. Ghosh S, May MJ and Kopp EB: NF-kappa B and Rel proteins: Evolutionarily conserved mediators of immune responses. Annu Rev Immunol 16: 225-260, 1998.

31. Van Antwerp DJ, Martin SJ, Kafri T, Green DR and Verma IM: Suppression of TNF-alpha-induced apoptosis by NF-kappaB. Science 274: 787-789, 1996.
32. Micheau O, Lens S, Gaide O, Alevizopoulos K and Tschopp J: NF-kappaB signals induce the expression of c-FLIP. Mol Cell Biol 21: 5299-5305, 2001

33. Thomas RP, Farrow BJ, Kim S, May MJ, Hellmich MR and Evers BM: Selective targeting of the nuclear factor-kappaB pathway enhances tumor necrosis factor-related apoptosisinducing ligand-mediated pancreatic cancer cell death. Surgery 132: 127-134, 2002.

34. Guttridge DC, Albanese C, Reuther JY, Pestell RG and Baldwin AS Jr: NF-kappaB controls cell growth and differentiation through transcriptional regulation of cyclin D1. Mol Cell Biol 19: 5785-5799, 1999.

35. Chen F, Castranova V and Shi X: New insights into the role of nuclear factor-kappaB in cell growth regulation. Am J Pathol 159: 387-397, 2001.

36. Dolcet X, Llobet D, Pallares J and Matias-Guiu X: NF-kB in development and progression of human cancer. Virchows Arch 446: 475-482, 2005

37. Sirotkin AV, Alexa R, Kišová G, Harrath AH, Alwasel S, Ovcharenko D and Mlynček M: MicroRNAs control transcription factor NF-kB (p65) expression in human ovarian cells. Funct Integr Genomics 15: 271-275, 2015.

38. Cafferata EG, Guerrico AM, Pivetta $\mathrm{OH}$ and Santa-Coloma TA: NF-kappaB activation is involved in regulation of cystic fibrosis transmembrane conductance regulator (CFTR) by interleukin-1beta. J Biol Chem 276: 15441-15444, 2001.

39. Lu Z, Ghosh S, Wang Z and Hunter T: Downregulation of caveolin-1 function by EGF leads to the loss of E-cadherin increased transcriptional activity of beta-catenin, and enhanced tumor cell invasion. Cancer Cell 4: 499-515, 2003. 